\title{
Discussion on the Importance of Selecting Balance System in Chemical Engineering Calculation
}

\author{
Yuexian Liu, Nanzhe Zhang* \\ College of Engineering, Yanbian University, Yanji, 133002, China \\ *Corresponding author: nzzhang@ybu.edu.cn
}

\begin{abstract}
Keywords: chemical engineering calculation; balance system; material balance
Abstract. Chemical engineering calculation is the basis of chemical engineering science and a required course for students of chemical engineering specialty. In chemical engineering calculation, the division and determination of the balance system are an important link. Taking the material balance as an example, the diversification and importance about the division and determination of the balance system in chemical engineering calculation were explained, the basic principles, some specific methods and skills about selecting the balance system were pointed out. In a word, the reasonable selection of the balance system in chemical engineering calculation can not only simplify the calculation and improve the efficiency, but also can avoid the errors.
\end{abstract}

\section{Introduction}

In chemical engineering production, for determining the process flow and operation conditions, selecting the equipment type, economic evaluation of chemical engineering process and so on, we all need to understand the consumption of raw materials, product output, energy consumption and their relationship with the process flow and operation conditions, therefore, we must carry on the quantitative calculation. Furthermore, the chemical engineering production have many characteristics such as many kinds of products, different process flow and parameters, different equipment types, many influencing factors for the process and high technical level. For example, in the rectification operation, if the feedstock and discharge of materials are not balanced, it will cause the operation is abnormal and the product quality is not qualified; in order to make the product quality as soon as possible to meet the standards, it needs the calculation according to the basic principle of material balance, and then guide the adjustment. There are many examples for using chemical engineering calculation to solve practical production problems. Therefore, if the personnel related to chemical engineering production master the basic knowledge of chemical engineering calculation, it is very important for chemical engineering process design, improving chemical engineering process operation, optimizing chemical engineering process flow, cost reduction, enhancing product quality and reducing the blindness of the production process.

\section{Material balance and balance system}

According to the contents, chemical engineering calculation include material balance, energy balance, calculation of material physical properties, equipment size calculation, pipeline calculation, equipment selection calculation, optimization calculation and so on, thereinto, material balance is the most basic and most important contents in chemical engineering calculation [1-3]. In the material balance, it is a very important problem to select the appropriate balance system. In general, it can get the correct answer to select the different balance system. However, if the balance system is selected properly, the calculation process can be simplified, the time of calculation can be shortened, and it can get twice the result with half the effort; contrariwise, the calculation process is complex, confused and easy to make mistakes. Especially in the material balance with cycle, emission or bypass procedure, we should pay more attention to the appropriate selection of balance system. For a chemical engineering process, how to divide and determine the balance system should be depended on the specific circumstances, and can not be made rigid provision. 
According to the characteristics of different chemical engineering process, the balance system selection should be noted the following points [4]: First, according to the number of known variables and solving variables, we need to design reasonable balance method, select the appropriate balance system in turn, list corresponding balance equations and then solve them. Second, the balance system should be selected properly, which combined with the selection and determination of calculating benchmark. For example, in the material balance, the stream with the most known variables should be selected as the calculating benchmark in general; if a chemical engineering process can be divided into several balance systems, we should select this balance system as the first balance system for the whole chemical engineering calculation, which the feedstock or discharge components of balance system are all known. Third, there are many equipments in a chemical engineering process, if each equipment is divided into balance system respectively, the independent equation numbers in the material balance $=$ the component numbers $\times$ the equipment numbers, obviously the equation numbers are more and balance is too complex. Therefore, in the material balance, the balance system are reasonably divided and determined according to the specific characteristics, as far as possible to reduce the equipment number, so that the independent equation numbers are least.

We explained the importance and some skills to select the balance system in chemical engineering calculation by using the following material balance as an example.

\section{The example}

There is a set of separation device which has two rectifying towers, the feedstock mixture with $50 \%$ benzene (B), 30\% toluene (T) and $20 \%$ xylene (x) (mol\%) is separated into relatively pure three fractions, the flow chart and each stream component are shown in Fig. 1, please calculate the molar flow rate of three fractions $S_{2}, S_{3}$ and $S_{4}$ when the molar flow rate of feedstock $S_{1}$ is $1000 \mathrm{kmol} / \mathrm{h}$.

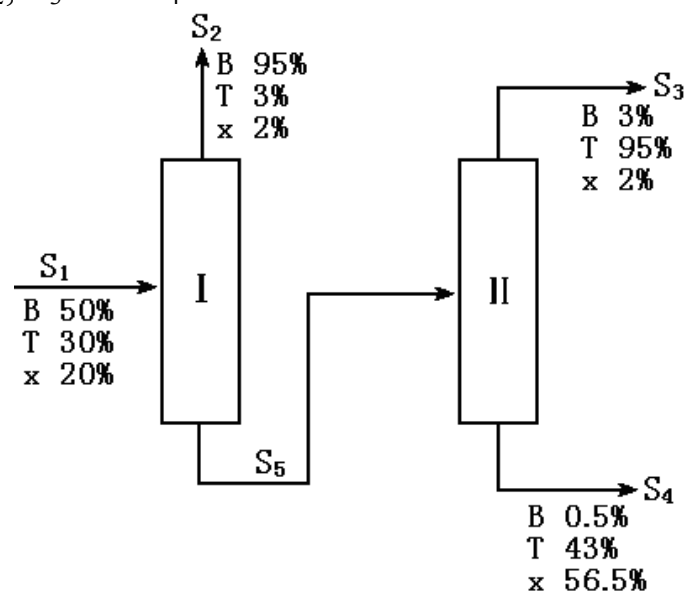

Fig.1 Material flow chart of rectification separation process

\section{The example analysis}

As shown in Fig. 1, there are five streams $\mathrm{S}_{1}, \mathrm{~S}_{2}, \mathrm{~S}_{3}, \mathrm{~S}_{4}$ and $\mathrm{S}_{5}$ in the whole rectification process, the components of $\mathrm{S}_{1}, \mathrm{~S}_{2}, \mathrm{~S}_{3}$ and $\mathrm{S}_{4}$ four streams are known, each of them can be selected as the calculating benchmark according to general principles of the calculating benchmark selection. But we take into account from the computational requirements, if the $S_{1}$ stream is selected as the calculating benchmark, we can directly obtain the solving variables by the balance calculation; otherwise the numerical values obtained by the balance calculation still have to convert into solving variables, one more step calculation process obviously increases the balance complexity.

When the $S_{1}$ stream is selected as the calculating benchmark, the rectifying tower I and tower II can be treated as a whole to select the balance system, the rectifying tower I and tower II can also be treated as the balance system respectively. Although these two division methods for the balance system can all calculate solving variables, the complex degree of the balance process differs greatly, and the calculating accuracy are often different, the details are as follows. 


\section{The division of different balance systems and their balance}

The first balance system. The rectifying tower I and tower II can be treated as a whole to select the balance system, as shown in Fig. 2.

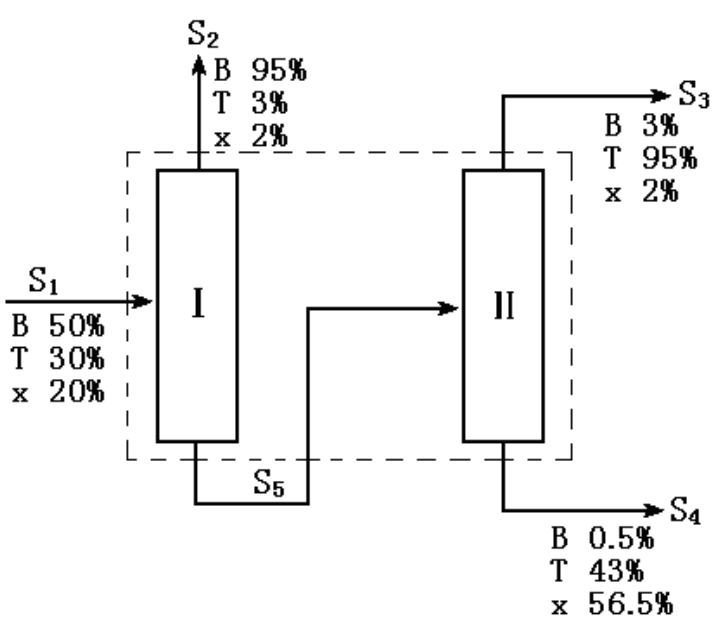

Fig.2 The balance system treated the rectifying tower I and tower II as a whole

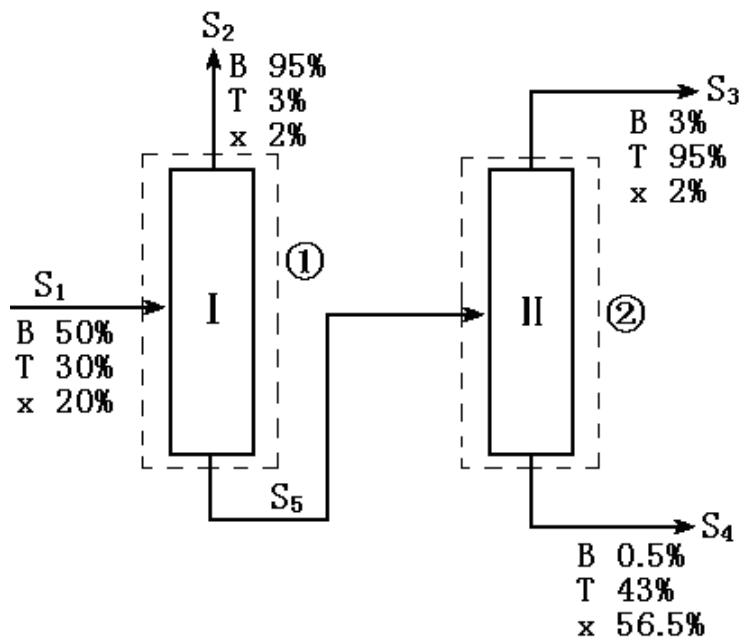

Fig. 3 The rectifying tower I and tower II treated respectively as the balance system

The calculating benchmark: $1000 \mathrm{kmol} / \mathrm{h}$ feedstock.

Because there are four streams (one stream is feedstock and the others three streams are discharge) and each stream has three components, there are only three independent material balance equations, namely:

The total material balance equation:

$1000=\mathrm{S}_{2}+\mathrm{S}_{3}+\mathrm{S}_{4}$

The component balance equation of benzene (B):

$1000 \times 0.5=0.95 \mathrm{~S}_{2}+0.03 \mathrm{~S}_{3}+0.005 \mathrm{~S}_{4}$.

The component balance equation of toluene $(\mathrm{T})$ :

$1000 \times 0.3=0.03 \mathrm{~S}_{2}+0.95 \mathrm{~S}_{3}+0.43 \mathrm{~S}_{4}$.

Simultaneous solving equation (1), (2), (3):

$\mathrm{S}_{2}=519.84(\mathrm{kmol} / \mathrm{h}) ; \mathrm{S}_{3}=149.88(\mathrm{kmol} / \mathrm{h}) ; \mathrm{S}_{4}=330.28(\mathrm{kmol} / \mathrm{h})$.

The second balance system. The rectifying tower I and tower II are respectively treated as the balance system, as shown in Fig. 3.

The calculating benchmark: $1000 \mathrm{kmol} / \mathrm{h}$ feedstock.

Because there are two balance systems (the balance system (1) and the balance system (2)) and five streams for feedstock and discharge, each stream has three components, so there are six independent material balance equations. Suppose the mole fraction of benzene, toluene and xylene was $\mathrm{X}_{5 \mathrm{~B}}, \mathrm{X}_{5 \mathrm{~T}}$, $\mathrm{X}_{5 \mathrm{x}}$ respectively in the $\mathrm{S}_{5}$ stream, then:

In the balance system (1):

The total material balance equation:

$1000=\mathrm{S}_{2}+\mathrm{S}_{5}$.

The component balance equation of benzene (B):

$1000 \times 0.5=0.95 \mathrm{~S}_{2}+\mathrm{X}_{5 \mathrm{~B}} \cdot \mathrm{S}_{5}$. 
The component balance equation of toluene (T):

$1000 \times 0.3=0.03 \mathrm{~S}_{2}+\mathrm{X}_{5 \mathrm{~T}} \cdot \mathrm{S}_{5}$.

In the balance system (2):

The total material balance equation:

$\mathrm{S}_{5}=\mathrm{S}_{3}+\mathrm{S}_{4}$

The component balance equation of benzene (B):

$\mathrm{X}_{5 \mathrm{~B}} \cdot \mathrm{S}_{5}=0.03 \mathrm{~S}_{3}+0.005 \mathrm{~S}_{4}$.

The component balance equation of toluene $(T)$ :

$\mathrm{X}_{5 \mathrm{~T}} \cdot \mathrm{S}_{5}=0.95 \mathrm{~S}_{3}+0.43 \mathrm{~S}_{4}$

Simultaneous solving equation (1), (2), (3), (4), (5), (6):

$\mathrm{S}_{2}=519.84(\mathrm{kmol} / \mathrm{h}) ; \mathrm{S}_{3}=149.88(\mathrm{kmol} / \mathrm{h}) ; \mathrm{S}_{4}=330.28(\mathrm{kmol} / \mathrm{h})$.

\section{Conclusions}

From the different solutions in the two kinds of balance system, it can be seen that the material balance equations in the first balance system are the linear equation groups in three variables, solving equation groups are relatively simple; but the material balance equations in the second balance system are the linear equation groups in six variables, the equation numbers are more, solving equation groups are relatively cumbersome, it's easy to make some mistakes in the balance process. Therefore, the division and determination of the first balance system are more reasonable than the second balance system.

We can visibly see from the above example, selecting the appropriate balance system can simplify the process of solving problems, reduce the workload and improve the computational efficiency, but also as far as possible to avoid some errors in the calculation process. Therefore, the balance system selection and its skills are very important in chemical engineering calculation and can not be ignored.

\section{References}

[1] Wenyuan Li, Bing Liu, Chemical Engineering Calculation, second ed., Chemical Industry Press, Beijing, 2011. In Chinese.

[2] Guijun Zhang, Fazhi Shen, Xue Xue, Chemical Engineering Calculation, second ed., Chemical Industry Press, Beijing, 2014. In Chinese.

[3] Zhirong Li, Yubin Yan, JOURNAL OF LULIANG HIGHER COLLEGE. 20 (2004) 70-71. In Chinese.

[4] Jianliang $\mathrm{Xu}$, Modern Chemical Engineering Calculation, first ed., Chemical Industry Press, Beijing, 2009. In Chinese. 